\title{
Dynamic analysis of scraper conveyor operation with external loads
}

\author{
Jerzy Świder ${ }^{1}$, Krzysztof Herbuś ${ }^{1}$, and Kamil Szewerda ${ }^{2, *}$ \\ ${ }^{1}$ Institute of Engineering Processes Automation and Integrated Manufacturing Systems, Faculty of \\ Mechanical Engineering, Silesian University of Technology, ul. Konarskiego 18a, 44-100 Gliwice, \\ Poland \\ ${ }^{2}$ The Laboratory of Virtual Prototyping Methods, The Institute of Mining Technology KOMAG \\ ul. Pszczyńska 37, 44-100 Gliwice, Poland
}

\begin{abstract}
A load to an armoured face conveyor (AFC) during coal mining is changeable and very difficult or even impossible to be predicted. Changes of the load to the upper scraper chain affect the load of the driving motor and generate changes in a scraper chain tension. Impact of increasing the external load to the upper scraper chain on the operation of electric motors and on the scraper chain tension is presented. The developed numerical model of the Rybnik 850 conveyor enabled identifying the places of the scraper chain high tension or places of its loosening. An impact of changing frequency of driving motor voltage on AFC's operational conditions was tested and analysed using the AFC's numerical model. During tests, tension of the scraper chain on the discharge end and the return end was recorded. High tension of the scraper chain and its loosening during the changeable load were also recorded on upward and downward transportation of run-of-mine material.
\end{abstract}

\section{Introduction}

Armoured face conveyors are the basic machines of a longwall system. The length of conveyors and the method of their installation (horizontal or inclined) are imposed by mining-and-geological conditions including a position of a coal seam. They operate in longwall panels in conditions of the changeable load, which is difficult to be predicted. The main component of the load results from the volume of the transported material. Chain tension and cooperation of conveyor's driving motors also have an impact on dynamic overloads. Majority of conveyors in Polish mines operate with constant (nominal) speed after a start-up phase. However, state-of-the-art conveyors have a possibility to be equipped with a frequency transducer. The use of the frequency transducer enables controlling the speed of conveyor movement, i.e. controlling its output [1 - 3].

Results of tests and numerical analyses aiming at identification of changes in load to conveyor driving motors in the case of the changeable load to the upper conveyor's chain, are presented. Numerical simulations were carried out on the developed computational model of RYBNIK 850 AFC. The impact of changes in the mains frequency of the electric

\footnotetext{
*Corresponding author : kszewerda@komag.eu
} 
motor (changes in settings of a frequency transducer) on dynamics of conveyor operation was also analysed.

\section{Computational Model}

The computational model consists of the physical model of RYBNIK 850 AFC and of the models of driving motors (Fig. 1). The physical model was built of rigid solids, geometric constraints, elastic-attenuating elements and contacts between the selected solids. The model was developed in MSC. Adams computer program, designed for analyses of kinematics and dynamics of multi-body systems. The model of electric motors was developed in MatLab/Simulink software environment. Frequency transducers, used to control speed of conveyor movement were also included.

After defining the output/input signals from both models, the physical model of the conveyor was connected with the model of electric motors. The operation of the conveyor was then simulated using the co-simulation technology [4 -9].

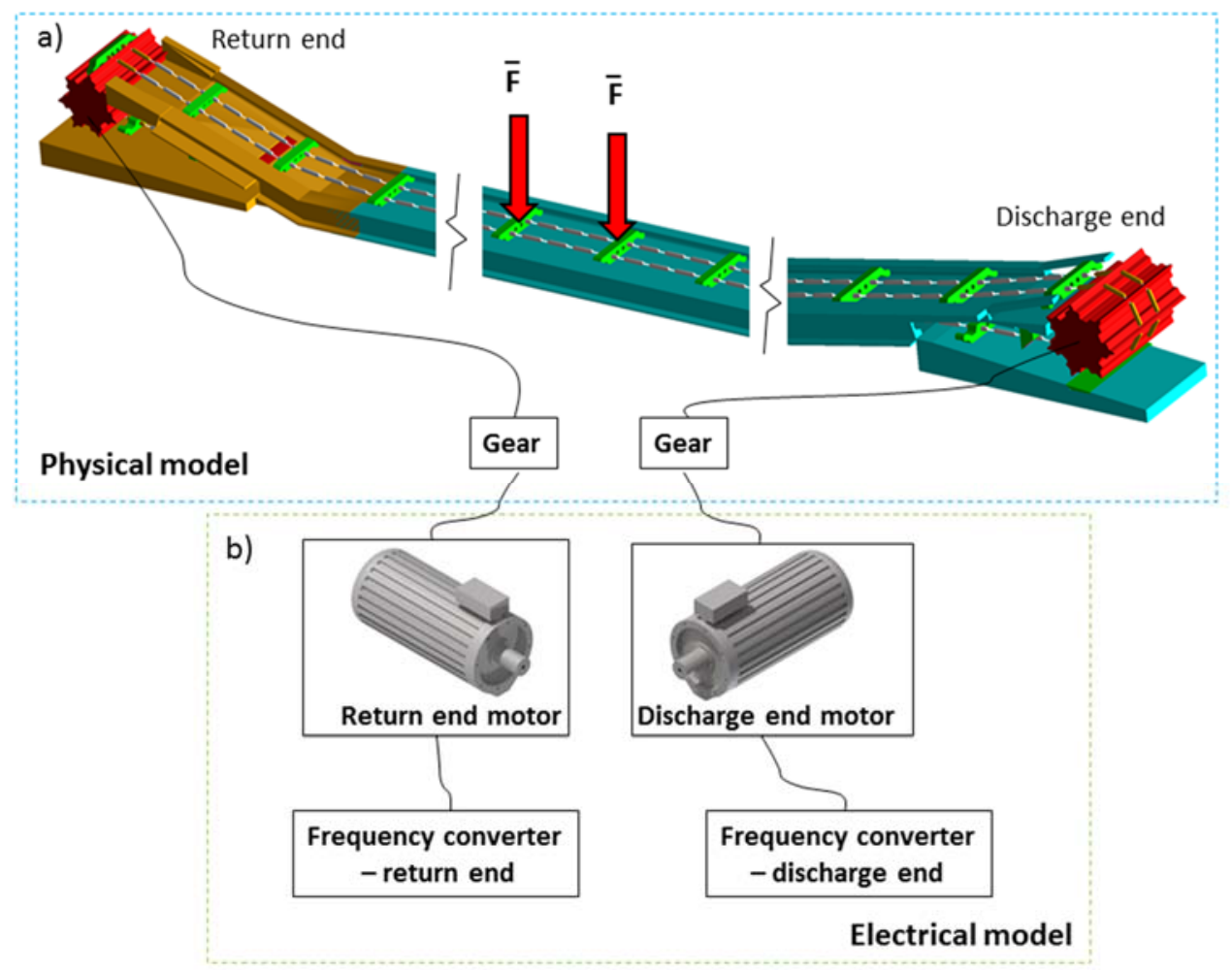

Fig. 1. Computational model of AFC a) physical model, b) electrical model [6].

Estimation of the load to the upper scraper chain is a difficult task and even impossible. Such load is of stochastic character. For numerical tests, vectors of forces $\bar{F}$, connected to centres of the selected scrapers (Fig. 1) were defined. Load to the upper part of the chain was then simplified to the friction force induced by the weight of transported run-of-mine. By changing the value of the load vector, movement resistance, which should be overcome by driving motors to move run-of-mine was increased or decreased. 


\section{Analysis of changes of current in motors under changes of a load value and voltage frequency}

Numerical simulations were carried out at the constant length of the conveyor (the distance between centres of driving drums at the discharge end and the return end) was not changed. The external load was changed by increase of the vector of the loading force from 0 to $400 \mathrm{kN}$ by $50 \mathrm{kN}$. Voltage frequency was $50 \mathrm{~Hz}$. During simulations, currents in electric motors of driving drums and torques were recorded. In Fig. 2 diagrams of minimum, maximum and average currents in the motor at the discharge end (a) and the returned end (b) of the conveyor in a function of load to the upper part of the conveyor's chain are presented.

a)

b)
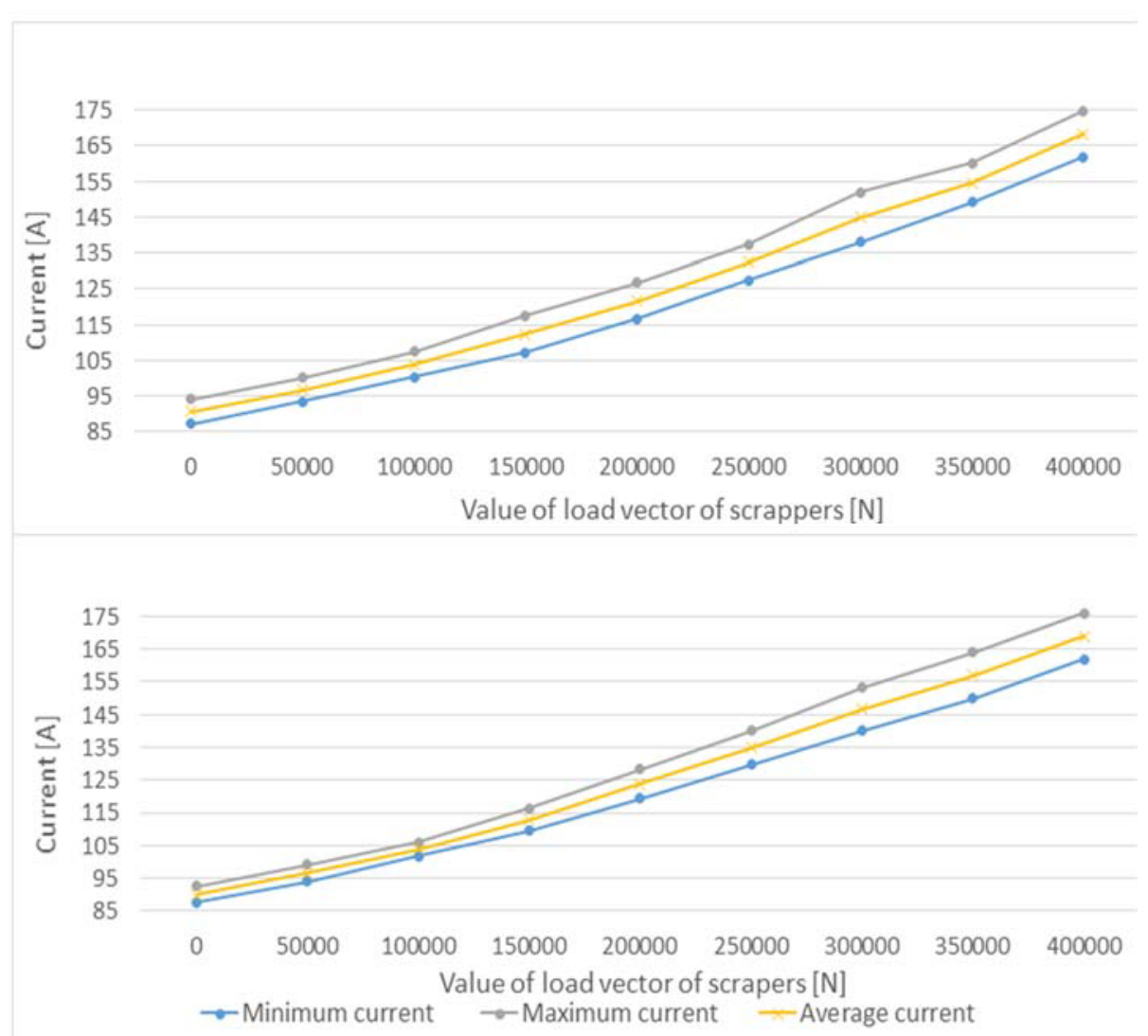

Fig. 2. Current in the motor a) at the discharge end b) at the return end in a function of the load to the conveyor [6].

Then changes in mains frequency of the electric motor by changing the setting of the frequency transducer in the motor's model were simulated. Simulations were carried out for the following frequencies $25 \mathrm{~Hz}, 35 \mathrm{~Hz}$ and $50 \mathrm{~Hz}$. At each frequency the conveyor was loaded by the force vector changed from 0 to $400 \mathrm{kN}$ with a skip $50 \mathrm{kN}$. Other boundary conditions in the computational model as well as the method of results recording were the same as in the previous case. In Fig. 3, average current recorded in the loaded (a) electric motor at the discharge end, (b) electric motor at the return end in a function of the conveyor load and mains frequency is given. 

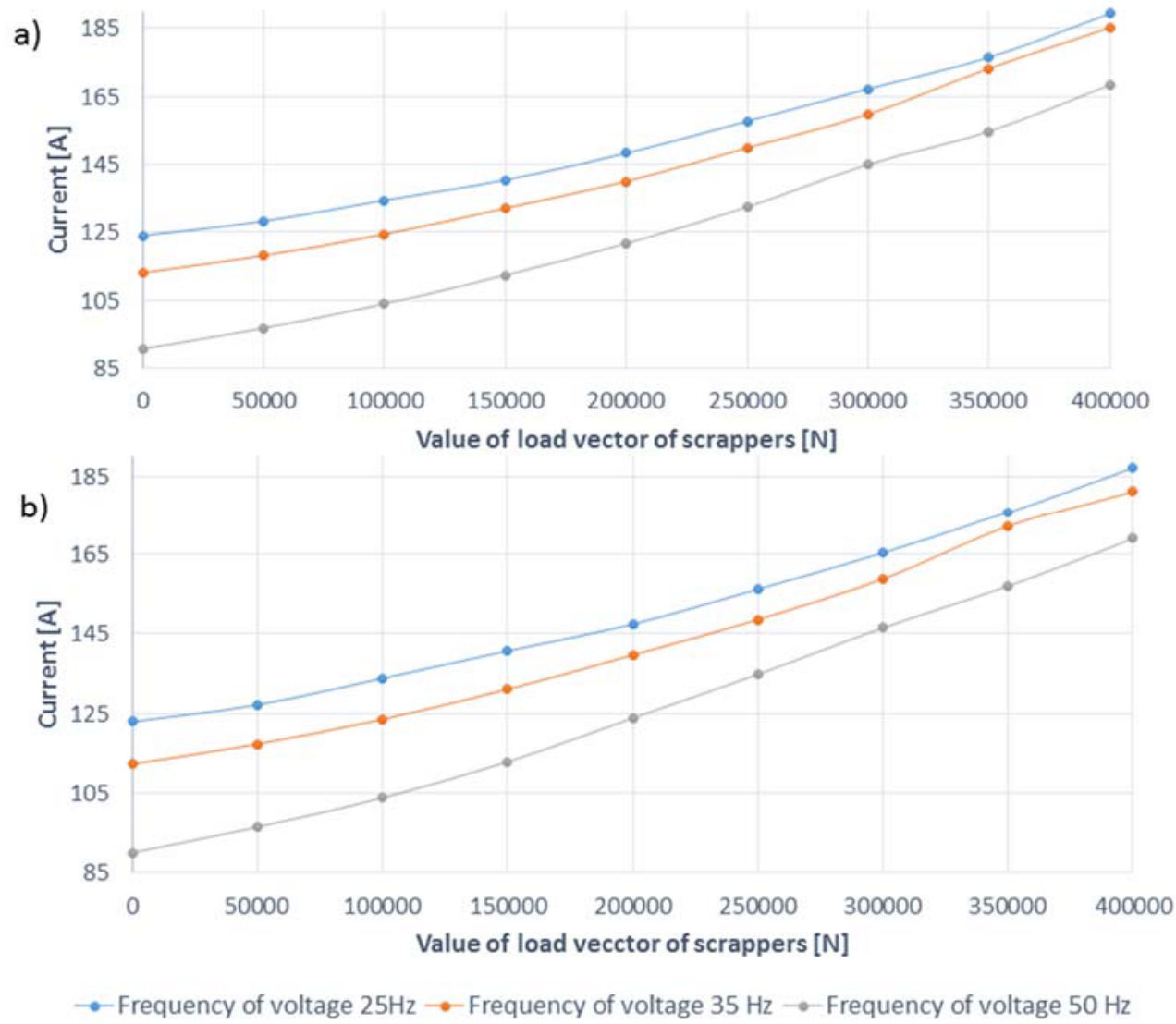

Fig. 3. Average current in electric motors in a function of the conveyor's load and mains frequency a) the motor located at the discharge end, b) the motor located at the return end [6].

Current in the electric motor was proportional to its load, what means that the motor generated a torque indispensable to balance the set load. When analysing the operation of the conveyor with two driving motors and assuming their correct cooperation, we found that the sum of torques generated by motors, including reducer's gear ratio, is equal to the sum of conveyor movement resistances. Considering that fact and the rule of current proportionality to the torque value, the current recorded in both motors was summed up. The sum of currents in the conveyor's motors in a function of the load, considering mains frequency, is presented in Fig. 4. 


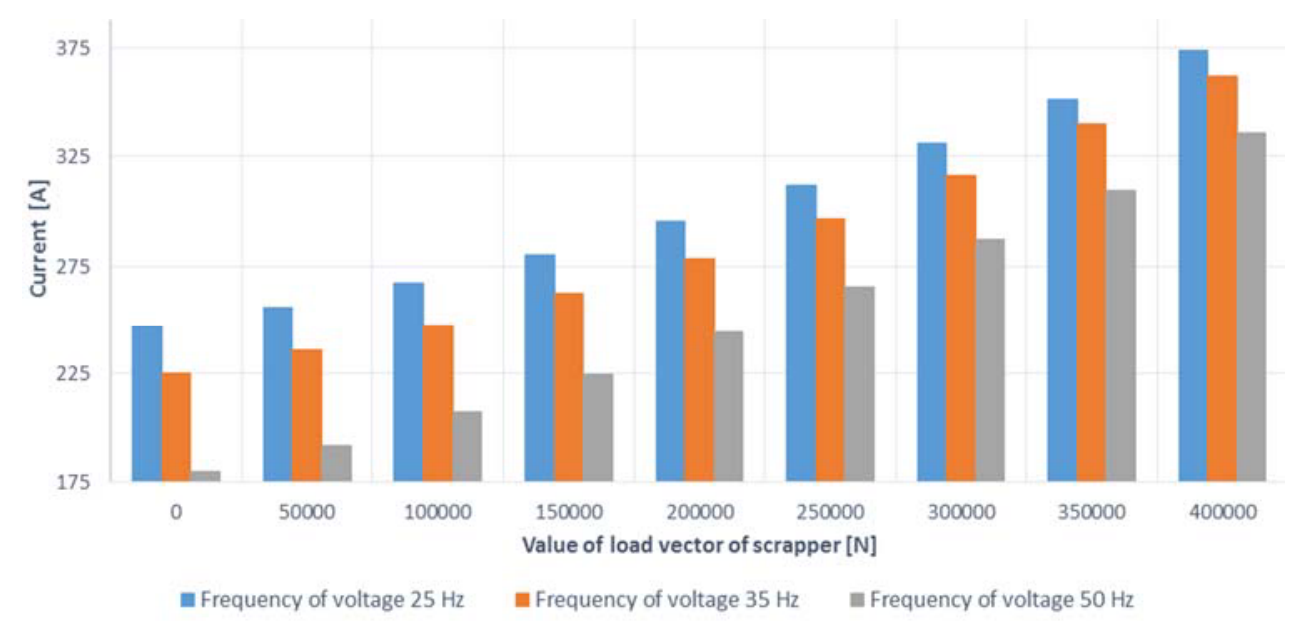

Fig. 4. Average sums of currents in electric motors in a function of the load to the conveyor, considering mains frequency [6].

It was also found that the increase of the load to the upper part of the chain resulted in the increase of current in electric motors. Reduction of motor's voltage frequency (reduction of its rotational speed) resulted in the increase of current at the same load to the conveyor. For example, the sum of currents in motors equal to 265 A was recorded:

- at mains frequency equal to $25 \mathrm{~Hz}$ with the load vector equal to $100 \mathrm{kN}$,

- at mains frequency equal to $35 \mathrm{~Hz}$ with the load vector equal to $150 \mathrm{kN}$,

- at mains frequency equal to $50 \mathrm{~Hz}$ with the load vector equal to $250 \mathrm{kN}$.

\section{Conclusions}

AFCs operating in hard coal mines as a part of a longwall system are exposed to a stochastic load, which results from a changeable volume of the transported run-of-mine. During simulation tests and analyses it was found that:

- the change in the load to the upper chain causes the change of torques generated by the motors; the generated torque is proportional to the current in electric motors,

- the sum of currents recorded in motors is proportional to the conveyor load at correct cooperation of both driving motors,

- the change in mains frequency of electric motors enables controlling the speed of conveyor movement, controlling its output at the same time; the change of mains frequency of electric motors causes change in motor's current, the reduction of mains frequency reduces a speed of the conveyor and increase of current in the electric motor at the same load to the conveyor,

- determination of the relationship between the change in mains frequency and current in motors will enable estimating the load to driving motors by measuring the current during the conveyor operation; then it will be possible to develop an algorithm for controlling operational parameters of the conveyor and at the same time to control its output. Development of this algorithm, which will control operational parameters of the conveyor (mains frequency and extension of return end of conveyor) will be the objective of future research work. 
The article is a result of the project realized within the doctoral grant financed by KOMAG Institute of Mining Technology.

Calculations were made on the computers of Centrum Informatyczne Trójmiejskiej Akademickiej Sieci Komputerowej (Academic Computer Center in Gdansk -TASK).

\section{References}

1. J. Przybyłka: Electric drives for belt conveyors with controlled rotational speed manufactured by DFME DAMEL S.A. Transport Przemysłowy i maszyny robocze $\mathbf{1 ( 2 7 )} / 2015,37$-39 (2015)

2. J. Suchoń: Mining scraper conveyors. The construction and use (KOMAG Institute of Mining Technology, Gliwice, 2012)

3. U. Paschedag, World Coal 18/6, 14-20 (2009)

4. J. Świder, K. Herbuś, K. Szewerda, J. Achiev. Mater. Manuf. Eng. 73/2, 165 - 175 (2015)

5. K. Herbuś, K. Szewerda, J. Świder, Model. Inż. 55, 34-41 (2015)

6. K. Szewerda: Method of parametrization and selection of algorithms for AFC's control. KOMAG Institute of Mining Technology (not published)

7. K. Herbuś, G. Kost, D. Reclik, J. Świder, Advanced Materials Research 837, 582-587 (2014)

8. K. Herbuś, P. Ociepka, IOP Conf. Series: Materials Science and Engineering 95 $012084(2015)$

9. P. Ociepka, K. Herbuś, IOP Conf. Series: Materials Science and Engineering 95 $012101(2015)$ 